\title{
POR QUE PÓS-MODERNISMO AGORA? COM VISTAS À POESIA DE ENACTMENT ${ }^{1}$
}

\author{
Susan Rudy \\ University of Calgary
}

\section{Resumo}

Preparado para um discurso no Canadian Literature Symposium da University of Ottawa (http: / / www.canlit-symposium.ca/), em maio de 2008, "Why Postmodernism Now? Toward a Poetry of Enactment" tem publicação prevista em Re:Reading the Postmodern (University of Ottawa Press), organizada por Robert Stacey. Nele, Rudy questiona tanto as razões para o retorno a questões do pós-modernismo no presente momento histórico e a suposta oposição entre estética e política em obras de teóricoschave. Propõe que examinemos as obras de poetas radicais no Canadá buscando exemplos de prática literária intimamente ligada ao engajamento político. O ensaio inclui leituras atentas das obras de Erín Moure, Jeff Derksen e Nicole Brossard.

Palavras-chave: Pós-modernismo, estética e política, poetas radicais canadenses. 
Escrevo porque é na linguagem que precisamos imaginar e ganhar nossa humanidade. Escrevo porque o presente éimensurável, permanentemente habitado por auroras e noites, séculos e culturas.

Nicole Brossard, She would be the first sentence of my next novel (1998:135)

Poesia como enactment, não consolo. É isso que espero, aguardo. E que não consumamos esperança como consumimos petróleo. Afinal de contas, não sobra muito dele.

Erin Moure2, “O YES” (2002:175)

Em sua chamada para trabalhos com base na obra de Fredric Jameson, os organizadores de "Re: Reading Postmodernism" pediram aos colaboradores que considerassem se o pós-modernismo poderia ser entendido melhor como "a lógica cultural dominante do capitalismo multinacional" ao invés de "um conjunto de tropos discursivos ou estilos literários". Gostaria muito de contestar essa definição de pósmodernismo que na realidade estabelece uma oposição entre estética e política, e que não está presente em Postmodernism, or, The Cultural Logic of Late Capitalism, de Jameson. Pelo contrário: ao final do primeiro capítulo, Jameson fala com anseio pelo ainda não realizado potencial da arte política. "A nova arte política," diz ele, terá que reconhecer "o espaço mundial do capital multinacional" sim; mas também deve ser "descoberta de algum novo modo ainda inimaginável de representar esse último, em que [...] recuperamos a capacidade de agir e lutar que no presente está neutralizada" (54). ${ }^{3}$ É minha argumentação que o que era para Jameson um "novo modo ainda inimaginável de representar" pode na verdade ser encontrado, não na ficção canadense-inglesa estudada por Linda Hutcheon em The Canadian Postmodern, mas nas poesias radicais que têm sido produzidas no Canadá e em outros lugares ao longo das últimas décadas.

Diferente de Jameson, que viu o espaço mundial pós-moderno do capital multinacional neutralizando a possibilidade da arte política, Hutcheon alegou que, na ficção canadense-inglesa ao menos, o pósmodernismo já era ligado a uma agenda política radical. Nem todos 
concordaram. Em 1990, Donna Pennee publicou uma resenha do livro um tanto devastadora criticando Hutcheon severamente por negligenciar responsabilidade por exatamente aquilo em que Hutcheon insiste e que nós leitores devemos reconhecer: "o fato de arte e teoria serem ambas práticas 'significantes' - em outras palavras, que somos nós que ao mesmo tempo fazemos e fazemos sentido de nossa cultura (23)" (Hutcheon citada em Pennee, 1990: 114). Pennee cita como exemplo convincente dessa negligência a desconexão entre o argumento de Hutcheon que o pós-modernismo foi "produto do ativismo político dos anos 60, da contínua desconstrução de sistemas na teoria literária atual, e especialmente da contribuição do feminismo àquela desconstrução" (109) e a efetiva falta de atenção a escritoras feministas. Como nota Pennee, Hutcheon dá "tanto a primeira quanto a última palavra sobre pós-modernismo canadense" (114) para Robert Kroetsch.

Quando Hutcheon reconhece a existência da poesia pós-moderna, é para argumentar que "o romance pós-moderno se desenvolveu de maneira paralela ao poema longo e documentário no Canadá" - "esse gênero narrativo/poético misturado" que ela considerou já "amplamente estudado como forma pós-moderna: sua história do épico ao poema modernista longo foi delineada; seu uso paródico de convenções narrativas para questionar a própria natureza do que implica a ordem do enredo narrativo foi estudado longamente" (13). ${ }^{4}$ Mas o poema longo e documentário no Canadá não é a única forma que poderia tomar a poesia radical. Além disso, "a nova radicalidade", como enfatiza Pauline Butling em "(Re)Defining Radical Poetics" (Writing in Our Time), inclui "figuras feitas minoritárias (mulheres, escritores(as) de cor, ou explicitamente poetas gays ou lésbicas" (2005: 19).

As poesias radicais hoje podem ser identificadas, não por seu engajamento com a ironia ou paródia pós-modernas, mas pelas afiliações de seus(as) escritores(as) com movimentos políticos radicais como aqueles mobilizados contra globalização, racismo, homofobia e misoginia. Além disso, como as citações com que abri esse ensaio sugerem, poesias radicais demonstram uma crença na possibilidade 
de esperança e uma renovada tentativa de "imaginar e ganhar nossa humanidade". É nessas poesias que "a nova arte política" a que se refere Jameson pode der encontrada.

$\mathrm{O}$ argumento que pretendo sustentar aqui sobre a eficácia das poesias radicais antecipa-se em The New Poetics in Canada and Quebec, de Caroline Bayard, publicado em 1989, apenas um ano depois de The Canadian Postmodern. O termo "poesias radicais" foi primeiro usado por Bayard que, como Hutcheon, descrevia um conjunto de práticas literárias e artísticas que, ao fim dos anos 80 , já tinha duas décadas de idade. Explicitamente basendo-se em L'Impureté, de Guy Scarpetta, ${ }^{5}$ Bayard demonstrou que as poesias radicais eram aquelas "impuras e abordagens estéticas ambiguamente hibridizadas que emergiram ao final dos anos 70" (1989: 4). Como Hutcheon, Bayard identificou a obra de Robert Kroetsch como central à compreensão do pós-modernismo no Canadá inglês nos anos 70 e 80 . Mas, diferente de Hutcheon, Bayard põe em evidência a obra da escritora feminista - Daphne Marlatt - como "essencial à percepção da postura pós-moderna nessa cultura" (156). Para contradizer o que também viu como "problemas postos pelos oponentes do pós-modernismo" (172), ela fornece evidência (na obra de Kroetsch, Marlatt e muitos outros) que "escrever não precisa satisfazer-se com relações pulverizadas e excessos de descarga. Pode também carregar material com possibilidades de significado, criar relações e não simplesmente demoli-las, e assim alcançar e desempenhar uma ação no mundo" (172). ${ }^{6}$

Mas ao invés de retomar Kroetsch e Marlatt, quero considerar como as poesias radicais contemporâneas "[carregam] material com possibilidades de significado" e "desempenham uma ação no mundo". Em sua sugestão de que pensemos na poesia, não como consolo, mas como enactment, Erin Mouré ecoa e amplia a noção de Jameson de uma arte política que nos possibilita recuperar nossa habilidade de agir no mundo (Bergvall e Moure "O YES", 2002: 175). A palavra enactment literalmente significa "uma portaria de uma 
autoridade legislativa, um estatuto" (Oxford English Dictionary). Mas olhando sua etimologia mais cuidadosamente vai nos levar ao significado que pretendo usar aqui, uma vez que a palavra enactment pode ser rastreada, não apenas como forma substantiva da palavra act, mas também por um significado da palavra relativamente pouco usado. O primeiro significado da palavra "act" como substantivo é "[uma] coisa feita; um feito, uma performance (de um ser inteligente)". Mas o sexto significado, "[um] registro de transações ou decretos; qualquer instrumento na escrita para verificar fatos", é igualmente útil aos nossos propósitos. Para um poeta, to enact poderia significar verificar fatos através da escrita; poesia como enactment dessa verificação, performance de um ser inteligente: é isso que Moure "espera, aguarda" (Bergvall e Moure "O YES", 2002: 175). Em "O YES", que Moure escreveu em colaboração com a escritora experimental inglesa e poeta de performance Caroline Bergvall, Moure continua: "A sociedade nunca pára de mudar, e isso, para pior, infelizmente, no momento. Talvez essas conversas que temos um com o outro, essas leituras, possam quebrar a queda um pouco. Se pudessem, um outro movimento seria possível" (175).

Em sua poesia, Mouré há muito nos convida para essa conversa, enacting aquilo que somos precisamente nesse sentido. Como escreveu em "The Anti-Anaesthetic," uma palestra oferecida em $1988^{7}$ na Kootenay School of Writing, em Vancouver:

Registro na Lei (em estágio de espelho) reduz a ansiedade para o organismo. Sua vinculação é dolorosa, mas é uma redução de ansiedade. Bem eficiente. Fornece as coordenadas de espaço, lugar. Mas para algumas pessoas, aquelas ausentes (mulheres, negros(as), nativos(as), lésbicas, classe trabalhadora, combinações disso), que não estão no centro mas nas arestas de marcos privilegiados, a Lei aumenta a ansiedade às vezes em um nível insuportável. Como lidar com isso? Bem, há uma espécie de força em ação, oposta 
àquela força centrífuga que é, ao invés disso, um empurrão para o centro, centrípeto. Uma anetesia. Para nos fazer esquecer, ou reprimir, ou definir em termos aceitáveis à ordem. (16)

Ambiguamente intitulado O Cidadán (2002), o livro mais recente de Moure coloca alguns dos ausentes - mulheres, lésbicas - no centro do texto, como diz ela, ao

"cruzar uma palavra: cidadão. [...] O cidadán. Uma palavra que reconhecemos embora não saibamos sua linguagem. Não pode ser encontrada em dicionários de português, espanhol ou francês. [...] Nesse livro, decidi que vou intervir nisso apenas com um movimento de discurso. Eu, uma mulher: o cidadán. Como se 'cidadão' em nosso tempo pudesse apenas ser desalojado quando falado em uma língua 'menor', uma historicamente persistente apesar das pressões internas e externas, e por uma mulher que porta - como lésbica em uma moldura cívica - uma sexualidade policiada" (itálico no original, n.p.)

Em O Cidadán, o filósofo narrador fala não da falta de profundidade pós-moderna ou da vacuidade do significante. No lugar disso, para Moure, o significante é tão "aquém de lotado" que tomba:

Se o significante fosse vazio, então os atos do cidadão seriam impossíveis, despropositados. E um chamado para um desarticular do eu das estruturas socializadas - ou para uma liberação de um povo de estruturas racializadas e políticas seria sem sentido ou absurdo. [...] A luta humana sempre se situa em corpos humanos. Não em corpos como significantes, mas como aparatos vividos (Fanon). Talvez, o significante é que seja aquém de lotado. Tomba. (itálico no original, 51) 
Em "The Anti-Anaesthetic", ela fala de seus anseios diante de "lacunas, dobras, realces que ao olho parecem arestas quebradas ou rupturas, onde você não consegue agarrar, mas tem que ouvir porque "isso torna o corpo presente como um leitor" (itálico no original, 17).

O mais recente método de Mouré para fazer o corpo presente como leitor tem sido na forma de tradução - ou o que ela chama de "transelation". Em suas "Notes in Recollection" no início de Sheep's Vigil by a Fervent Person, Mouré fala de seu motivo para incluir os originais em português: quer que o livro seja julgado, não só por sua poesia, mas pelas traduções de O Guardador de Rebanhos, de Pessoa, (escrito sob o heterônimo de Alberto Caeiro) ${ }^{8}$ que ela chama "Trans-elations. Trans-eirin-elations. Transcreations" (ix). Ao inserir a grafia do seu nome - eirin - na palavra "transelation," exemplifica como, para ela, "[a] prática da leitura é sempre incorporada. Uma tradução sempre traduz uma prática de leitura enacted em um texto" (Moure "Hi Fidelity!", n.p.). Além disso, a prática de leitura enacted nesse texto se estende a uma prática de escrita que engaja um outro: "Traduzi Pessoa respondendo a ele como pessoa. Eu, uma pessoa, e Pessoa, uma pessoa. Pois em português, person é pessoa" (viii).

Assim como a noção de "transelation" põe em evidência a presença de um tradutor incorporado, Jeff Derksen também se preocupa com o modo em que o escritor tanto é habitado por algo que parece ser concedido e penetrante e ainda assim resiste a isso, no seu caso, o capitalismo global: "I walk by / my previous text / A human being is not born / as an abstract / biological organism but [...] / In this sense / I am inhabited" (1993: 25). Para Derksen, esse habitar e resistir é possível porque o discurso de capitalismo global, a que mais adiante se refere como narrativa dominante do neoliberalismo, pode ser rearticulado, penetrado, como um poema. Além disso, esses discursos podem penetrar um poema e, ao fazer isso, podem ser desalojados de seu status de narrativa dominante.

Considere o seguinte excerto de outro poema inicial também publicado em Dwell (1993): 
Here the light

to heavy industry

doesn't mar the river

as much as it now

makes it.

New. Compensation's body

is a green image, arms

filled with lumber. But production's

miracle is its occurrence, oiling

a century. Our role

is the crisis. Sliding

so I can clarify

a centralized management

in this continuous present

of product, "excess," resource.

("Phatic Weather" 23-24)

Como demonstra esse poema, assim como o de Mouré, a poesia de Derksen também se preocupa com resistências mas de uma maneira diferente: através de um engajamento com geopolítica, economia e as "reais relações" que são obscurecidas pelas ideologias dominantes.

Desde a virada do século XXI, Derksen tem complementado suas investigações em poesia com uma série de falas e ensaios que abertamente criticam a política do que identifica como neoliberalismo ou "poderosa ideologia de senso comum da globalização" "Poetry and the Long Neoliberal Moment", 2006: 5). Em "Poetry and the Other Politics," por exemplo, trabalho apresentado em uma sessão sobre "Poetry and Politics" no encontro do MLA in Washington, 2005, Derksen identifica neoliberalismo como "a política" que ele está "tentando processar, entender, desacreditar, ridicularizar e na qual lançar uma dura luz" (41). Nesse estudo, ele aborda o sujeito do pós-modernismo 
em sua relação com o neoliberalismo quando nota que "as narrativas dominantes da modernidade, imaginadas aos pedaços ou sem controle no terreno pós-moderno, no entanto, retornaram como narrativas dominantes neoliberais" (43). A poesia de Derksen lança uma dura luz especial na mais poderosa narrativa dominante de neoliberalismo: a economia. Considere, por exemplo, "Sly Consumption Side Sentence" de Transnational Muscle Cars (2003):
Dear neoliberalism, I just want to thank you for letting me be a mobile self-reflexive commodity with agency putting no pressure on former state structures anew, again till you use me up consumption side just like you did production side with Dad add an e, dead (121)

Como Derksen diz abertamente em "Poetry and the Other Politics: Neoliberalism and Culture," "determinantes econômicos não são abstratos [...] - nós os vemos, caminhamos através deles, vivemos neles [ou, francamente morremos por causa deles] diariamente" (2006: 41).

Derksen assim declara em "Jerk", o poema que serve de prefácio para Transnational Muscle Cars:

[...] I want to see the real relations 
but you've got Nikes on and I like you so I have to try and understand. And if that shirt's from The Gap, then one arm was sewn in Malaysia, the other in Sri Lanka. Why then is it hard to "see" ideology when you're wearing it? (10)

A publicação mais recente de poesia de Derksen intitula-se "The Vestiges (or, Creative Destruction)" (2006), do livro The Soft Coup, um manuscrito em andamento que abertamente "processa" o discurso da economia neoliberal. Segue um excerto:

We don't negotiate

with workers or terrorists post-Thatcher

post-Mulroney

post-Reagan

post-Kohl

post-NAFTA

post-market bubble

post-industrial

post-port city

post-tin-pot grab-and-go neo-con local cronies:

Bennett, Harris, Klein, Giuliani, Campbell interchangeable [add your own] (36)

Quando a palavra "vestige" (vestígio) é usada no plural, como é no título do texto de Derksen, significa "memorial de sobrevivência ou traço de alguma condição, qualidade ou prática, etc., servindo como indicação de sua existência anterior" (Oxford English Dictionary), sugerindo que o poema pode simplesmente "traçar" os últimos vestígios de democracia, 
aquilo que existia antes desses particulares "pós": pós-NAFTA, Reagan, Thatcher. Acrescente mesmo seus próprios "pós".

O uso de Derksen do termo "Creative Destruction" ("Destruição Criativa") como subtítulo para "The Vestiges" ("Os Vestígios") abertamente sinaliza o reenactment do discurso da economia neoliberal. O economista Joseph Schumpeter, no seu livro Capitalism, Socialism and Democracy (1942), cunhou a frase "destruição criativa", para descrever o processo de transformação que acompanha inovação radical. Em capítulo sobre "The Process of Creative Destruction," Schumpeter descreve esse "processo de mutação industrial" como "fato essencial" pois "incessantemente revoluciona a estrutura econômica pelo lado de dentro, incessantemente destruindo a antiga, incessantemente criando uma nova" (1987: 83). O livro de Thomas K. McCraw (2007) sobre Schumpeter como profeta da inovação delineia diversos exemplos que Schumpeter usou para "descrever como produtos e métodos capitalistas inovadores continuamente deslocam os antigos. [...] A fábrica fez desaparecer a oficina do ferreiro, o carro substituiu o cavalo e a charrete, e a empresa derrubou a propriedade" (3). Em seu trabalho sobre neoliberalismo, Derksen baseia-se muito nos escritos do geógrafo cultural David Harvey que, em seu ensaio "Neoliberalism as Creative Destruction", ${ }^{9}$ também sustenta o seguinte argumento:

A criação desse sistema neoliberal ocasionou muita destruição, não apenas de estruturas e poderes institucionais anteriores (tais como a suposta soberania do estado sobre questões político-econômicas) mas também de divisões de trabalho, relações sociais, políticas de assistência social, arranjos tecnológicos, modos de vida, pertencimento a terra, hábitos do coração, formas de pensamento, e assim por diante. Há que se fazer alguma avaliação dos aspectos positivos e negativos dessa revolução neoliberal. (23) 
Em justaposições irônicas, "The Vestiges" oferece uma considerável avaliação dos efeitos negativos na "inovação" neoliberal:

Gas gouging? How

Seventies!

Monopolies? How

Lenin!

Child labour? How

Dickens!

Bombing Baghdad

again? How nineties!

War crimes? How Kiss-

inger!

Apocalyptic

weather patterns? How

Sci-fi!

Urban regeneration? How

organic!

Sustainable cities? How to

oust non-owners?

(2006: 39)

Esse poema aparece em "Poetry and the Long Neoliberal Moment", edição especial do periódico West Coast Line, organizado por Derksen. Essa edição focaliza o que Derksen identifica em outro escrito como "um corpo crescente de poesia na América do Norte que está criticamente e intensivamente engajado com a política e a 
reestruturação trazidas pelo neoliberalismo" ("National Literatures in the Shadow of Neoliberalism", 2007: 19). Derksen reúne obras dos poetas Rita Wong, Donato Mancini e Stephen Collis de Vancouver; Arol Mirakove, Kim Rosenfield e Rodrigo Toscano de New York City; Mark Nowak de Minneapolis, Hung Tu de San Diego, e Tyrone Williams de Cincinnati.

Em sua introdução, Derksen fala de seus poemas como "atos de produção de conhecimento" (10), que descreve, usando palavras da epígrafe "Re:evolution" de Kim Rosenfield, como vindos "Out of the blue, to you, for whom today is difficult" (118). Também na introdução, cita uma fala da poeta norte-americana Juliana Spahr em outro painel do MLA sobre poesia. Isso aconteceu em dezembro de 2001 e, apropriadamente, teve o título de "Poetry in a Time of Crisis." Spahr fala de como "escrever e ler é importante pelo modo como pode nos levar através do conforto e da estética para relações com outros, pelo modo como pode modelar o pensamento" (n.p.). Diz que quer "mais poesias de conexão no futuro. Mais poemas lidando com as complexas questões de como falar um com o outro. Mais poemas que reconheçam como isso é difícil. Mais poemas que olhem para fora" (n.p.)

O que Spahr articula aqui, penso eu, é a chave para se entender o que é exigido de nós no presente. Na verdade, não se trata de retorno a questões de pós-modernismo. Ao invés disso, um movimento em direção ao outro e ao mundo: o que Moure chamaria de poesia de enactment. Como Miriam Nichols, crítica de Vancouver, recentemente salientou, em "Toward a Poetics of the Commons", recém publicada em Antiphonies: Essays on Women's Experimental Poetries in Canada (2008), o projeto de ampliar "pessoalidade para toda a humanidade" (157) está longe de terminar; precisamos agora entender nossas comunalidades como também nossas diferenças:

Ao escrever isso, não resta aspecto algum da vida intocado pelos processos de globalização. Entre os efeitos estão um declínio de autonomia dos estados da nação e um 
correspondente déficit democrático, concentração de riqueza nas mãos de uma pequena classe proprietária, privatização de recursos essenciais como água e sementes, patenteamento de formas de vida, destruição de habitats ecológicos e culturais, empobrecimento de populações inteiras. Essa é agora a nossa condição, não o noticiário. (146)

O ponto principal de Nichols não é, no entanto, que nossa "condição" ameaça os termos de nossa humanidade, mas que nós "na área de humanidades não produzimos uma visão alternativa, forte, para a prevalente visão de mundo neoconservadora porque a diferença - diferença social e também difference- parece levar para o relativismo ético e cultural" (147). Como Brossard e Mouré, Nichols trabalha com e sem esperança, ambas firmemente acreditando que "leituras mais matizadas do legado pós-moderno e das práticas de arte contemporânea renderiam uma história diferente da que temos" e que a escrita experimental nos oferece meios de imaginar "um novo universo humano" (147).

Quero finalizar engajando-me de novo com o universo humano evocado na obra da poeta radical, feminista, Nicole Brossard. Notebook of Roses and Civilization, de Brossard, tradução de seu livro Cahiers de roses et de civilisation para o inglês (por Robert Majzels and Erín Moure, 2003) consiste em seis sessões, sendo a segunda, quarta e sexta poemas em prosa de uma página intitulados "Soft Link 1", "Soft Link 2" e "Soft Link 3". Neles Brossard nos lembra do sempre presente "lado de fora" da poesia:

But there is outside, the cold the heat the violence doubled over in pain in a real bind at the edge of the city and forest, there's outside and it's worse each time as there's traffic of weapons, traders of women and children, white-shirted men who manipulate our genes and cells like so much merchandise. (57) 
Ainda assim ela retorna para esse "lado de fora" muitas vezes, lembrando que para "ganharmos nossa humanidade" temos que repetidamente lembrar o lado de dentro do lado de fora que a poesia sempre habita. A terceira sessão do livro, também intitulada "Notebook of Roses and Civilization", abre com um poema "to understand how / people bend / before an idea / their hair barely brushing the depth of silence" (20). Silêncio, cabelos, idéias, poemas - isso tudo é a matéria de poesias radicais, que não apenas estão no mundo, são um mundo para o qual podemos nos voltar, dos nossos silêncios. O livro termina com "Soft Link 3": "nomes de lugares, cidades climas que assombram" (81). E essa obra tem tudo a ver com nos assombrar. Não uma fuga do mundo, mas uma entrada para ele, um ser encantado por ele, como pbNichol sugeriu há mais de vinte anos:

Doorway. Frame. Mouth. Opening. Passage. The trick is to get from

there to here thru her. Or the way Ellie misread that sign on the high-

way for years: RIGHT LANE MUST EXIST. And of course it's the old

conundrum - the exit's the entrance. Exit Ma \& I exist. And when I

fell in love with Ellie I was entranced. Into a world. The world. This world. Our world. Worlds. (Selected Organs 11)

\section{Notas}

1. A versão original do ensaio de Susan Rudy, "Why Postmodernism Now? Toward a Poetry of Enactment" será publicada em RE:Reading the Postmodern, coletânea organizada por Robert Stacey (Ottawa: U Ottawa P, 2010). Reproduzido com permissão da University of Ottawa Press. 
2. A poeta que originalmente publicava com o nome de Erin Mouré agora escreve seu nome de diferentes formas dependendo do contexto; sua obra é citada aqui sob os nomes de Erin Mouré, Erín Moure e Eirin Moure. Para uma discussão perspicaz do fato que "quanto mais seu trabalho como poeta e tradutora prolifera, mais também seus nomes" (167), ver seus comentários sobre a escritora experimental inglesa e poeta de performance Caroline Bergvall em Bergvall e Moure's "O YES".

3. N.T. Traduzo aqui todas as citações críticas em inglês, mantendo as referências originais.

4. Hutcheon não fornece evidência substancial para esse argumento, uma vez que suas únicas referências para esse amplo estudo se encontram em uma única nota em que cita o ensaio de Robert Kroetsch, "For Play and Entrance: The Contemporary Canadian Long Poem" (1981) e a introdução de Michael Ondaatje's para The Long Poem Anthology (1979).

5. Obra que ainda não foi traduzida para o inglês.

6. Em Writing in Our Time, repetidamente voltamos a Dapnhe Marlatt e marcamos suas contribuições - não só como poeta, mas editora, organizadora de conferência e tradutora.

7. Publicado subseqüentemente como "Wanting it Other/Wise: Race, Sexualities, Bodies, Texts", Open Letter 9.3 (1995): 13-21.

8. Para mais dados sobre o grande poeta modernista português Fernando Pessoa e seu hábito de escrever sob heterônimos, ver "A Note on Fernando Pessoa" ao final de Sheep's Vigil, de Moure.

9. Harvey identifica neoliberalismo como aquelas práticas econômicas que propõem que "o bem estar humano pode ser melhor antecipado ao liberar liberdades e habilidades empresariais individuais dentro de um quadro institucional caracterizado por fortes direitos de propriedade, mercados livres e livre comércio" (Harvey 2). De forma ainda mais direta, nas palavras de Harvey, "neoliberalismo é acima de tudo um projeto para restaurar a dominação de classe a setores que viram suas fortunas ameaçadas pela ascensão social dos esforços democráticos em conseqüência da Segunda Guerra Mundial" ("Neoliberalism as Creative Destruction", 2007: 22). 


\section{Referências}

BAYARD, Caroline. The New Poetics in Canada and Quebec: From Concretism to Post-modernism. Toronto: University of Toronto Press, 1989.

BERGVALL, Caroline; MOURE, Erín. OYES. In: DORWOOD, Nate(Ed.). Antiphonies: Essays on Women's Experimental Poetries in Canada. Willowdale: The Gig Press, 2008, pp. 167-176.

BROSSARD, Nicole. Notebook of Roses and Civilization. Trad. Robert Majzels e Erín Moure. Toronto: Coach House Books, 2007. Tradução de Cahier de roses et de civilisation. Trois-Rivières: Éditions d'art le Sabord, 2003.

BROSSARD, Nicole. She would be the first sentence of my next novel / elle serait la première phrase de mon prochain roman. Trad. Susanne de Lotbiniè1234reHarwood. Toronto: Mercury Press, 1998.

BUTLING, Pauline; RUDY, Susan. Writing in Our Time: Canada's Radical Poetries in English (1957-2003). Waterloo: Wilfrid Laurier UP, 2005.

DERKSEN, Jeff. Dwell. Vancouver: Talonbooks, 1993.

DERKSEN, Jeff. From: The Vestiges (or, Creative Destruction). West Coast Line, v. 40, n. 3, 2006. pp. 32-40.

DERKSEN, Jeff. National Literatures in the Shadow of Neoliberalism. Disponível em: <http://www.transcanadas.ca/ transcanada2_pos.html>. Accesso em: 1 Maio 2008.

DERKSEN, Jeff. Poetry and the Long Neoliberal Moment. West Coast Line, v. 40, n. 3, 2006. pp. 4-11.

DERKSEN, Jeff. "Poetry and the Other Politics: Neoliberalism and Culture." West Coast Line, v. 39, n. 3, 2006. pp. 41-45.

DERKSEN, Jeff. Transnational Muscle Cars. Vancouver: Talonbooks, 2003.

DORWOOD, Nate, ed. Antiphonies: Essays on Women's Experimental Poetries in Canada. Willowdale: The Gig Press, 2008. 
HARVEY, David. Neoliberalism as Creative Destruction. The Annals of the American Academy of Politic and Social Science, v. 610, 2007. pp. 21-44.

HUTCHEON, Linda. The Canadian Postmodern: A Study of Contemporary EnglishCanadian Fiction. Toronto: Oxford UP, 1988.

JAMESON, Fredric. Postmodernism, or, the Cultural Logic of Late Capitalism. London: Verso, 1991.

KROETSCH, Robert. For Play and Entrance: The Contemporary Canadian Long Poem. Dandelion, v. 8, 1981. pp. 61-85.

MCCRAW, Thomas K. Prophet of Innovation: Joseph Schumpeter and Creative Destruction. Cambridge, Massachusetts: The Belknap P of Harvard UP, 2007.

MOURE, Eirin. Sheep's vigil by a fervent person: A transelation of Alberto Caeiro/ Fernando Pessoa's O guardador de rebanhos. Toronto: Anansi Press, 2001.

MOURE, Erín. O Cidadán. Toronto: Anansi Press, 2002.

MOURÉ, Erin. The Anti-Anaesthetic. Wanting it Other/Wise: Race, Sexualities, Bodies, Texts. Parte 2, edição especial de Open Letter, v. 9, n. 3, 1995. pp. 13-21.

MOURÉ, Erin. Hi, Fidelity! or Translating Fernando Pessoa: Felicity was Ever My Aim, Poetics.ca, n. 4, Fall 2004. Acesso em: 5 Maio 2008.

NICHOL, bp. Selected Organs: Parts of an Autobiography. Windsor: Black Moss Press, 1988.

NICHOLS, Miriam. Toward a Poetics of the Commons: O Cidadán and Occasional Work. In: In: DORWOOD, Nate (Ed.). Antiphonies: Essays on Women's Experimental Poetries in Canada. Willowdale: The Gig Press, 2008, pp. 146-166.

ONDAATJE, Michael. Introduction: What is in the Pot. In: ONDAATJE, Michael Ondaatje (Ed.) The Long Poem Anthology. Toronto: Coach House Press, 1979, pp. 10-18.

PENNEE, Donna. A postmodern engagement. Revisão de The Canadian Postmodern de Linda Hutcheon. Essays on Canadian Writing, v. 41, 1990. pp. 109-115. 
ROBERTSON, Lisa. Occasional Work and Seven Walks from the Office for Soft Architecture. Astoria, Oregon: Clear Cut Press, 2003.

ROSENFIELD, Kim. Re:evolution. West Coast Line, v. 40, n. 3, 2006. p.118.

SCARPETTA, Guy. L'Impureté. Paris: Bernard Grasset, 1985.

SCHUMPETER, Joseph A. The Process of Creative Destruction. In: Capitalism, Socialism and Democracy. 1942. London: Unwin Paperbacks, 1987. pp. 81-86.

SPAHR, Juliana. "Poetry in a Time of Crisis." < http://people.mills.edu/jspahr/ poetrycrisis.htm.> Acesso em: 23 Abril 2008.

Tradução de Maria Lúcia Milléo Martins 
